\title{
Outcome and human epidermal growth factor receptor (HER) 1-4 status in invasive breast carcinomas with proliferation indices evaluated by bromodeoxyuridine labelling
}

\author{
Sian M Tovey, Caroline J Witton, John MS Bartlett, Peter D Stanton, Jonathan R Reeves \\ and Timothy G Cooke
}

\begin{abstract}
Endocrine Cancer Group, Division of Cancer Sciences and Molecular Biology, University Department of Surgery, Glasgow Royal Infirmary, Glasgow G31 2ER, UK

Corresponding author: John MS Bartlett (e-mail: j.m.bartlett@clinmed.gla.ac.uk)
\end{abstract}

Received: 27 Nov 2003 Revisions requested: 10 Feb 2004 Revisions received: 20 Feb 2004 Accepted: 4 Mar 2004 Published: 23 Mar 2004

Breast Cancer Res 2004, 6:R246-R251 (DOI 10.1186/bcr783)

(C) 2004 Tovey et al., licensee BioMed Central Ltd. This is an Open Access article: verbatim copying and redistribution of this article are permitted in all media for any purpose, provided this notice is preserved along with the article's original URL.

\begin{abstract}
Background: We have shown previously that whereas overexpression of human epidermal growth factor receptor (HER) 1, HER2 and HER3 is associated with poor prognosis in breast cancer, HER4 is associated with a good prognosis. Cell proliferation is a key component of aggressive cancers and is driven by growth factors. In this study, bromodeoxyuridine (BrdU)-derived proliferation indices are correlated with clinical outcome and HER1-4 status for further clarification of the differing roles for the HER family at a biological level.
\end{abstract}

Methods: Seventy-eight invasive breast cancers had BrdU labelling in vivo to determine the BrdU labelling index (BLI) and the potential tumour doubling time $\left(T_{\text {pot }}\right)$. Long-term clinical follow-up was available for these patients. We used immunohistochemistry to establish the HER1-4 status in 55 patients from the BrdU cohort.
Results: We demonstrate a significant correlation between high BLI values and breast cancer-specific death $(P=0.0174)$. Low $T_{\text {pot }}$ times were also significantly correlated with breast cancer-specific death $(P=0.0258)$. However, BLI did not independently predict survival in Cox's multiple regression analysis when combined with other prognostic factors such as size, grade and nodal status. Tumours found to be positive for HER1, HER2 or HER3 had significantly $(P=0.041)$ higher labelling indices, with HER1 also showing significantly higher indices when considered independently $(P=0.024)$. Conversely, HER4 positivity was significantly correlated $(P=0.013)$ with low BLI values, in line with previous data associating this receptor with good prognosis tumours.

Conclusions: These results support the hypothesis that HER $1-3$ are associated with driving tumour proliferation, whereas HER4 is involved in a non-proliferative or even protective role.

Keywords: breast cancer, bromodeoxyuridine, HER1, HER2, HER3, HER4

\section{Introduction}

High rates of cellular proliferation are a key component of aggressive breast cancers. Markers of proliferation, such as Ki67, are widely used to identify cancers with high proliferative indices and have the potential to alter treatment rationale [1-3]. In addition, determining cellular proliferation rates provides an insight into the intrinsic biology of a tumour, indicating the degree of growth stimulation that is contributing to increasing tumour size. The human epidermal growth factor receptor (HER) family of receptor tyrosine kinases forms part of a complex signal cascade modulating cell proliferation, survival, adhesion, migration and differentiation. The family comprises four homologous receptors, HER1 (EGFR/ErbB1), HER2 (ErbB2/neu), HER3 (ErbB3) and HER4 (ErbB4) [4]. Overexpression of all four receptors has been observed in

$\mathrm{BLI}=$ bromodeoxyuridine labelling index; BrdU = bromodeoxyuridine; $\mathrm{ER}=$ oestrogen receptor; $\mathrm{HER}=$ human epidermal growth factor receptor; $T_{\text {pot }}$ $=$ potential tumour doubling time. 
breast cancer [5-8]. We have recently shown that patients with overexpression of HER1-3 exhibit markedly reduced survival, whereas patients with overexpression of HER4 demonstrate increased survival in comparison with patients not expressing high levels of any of these receptors [9]. There is published evidence suggesting that HER4 is less able to recruit proliferative (RAS/RAF) signal transduction pathways than other HER family members $[4,10]$. We have therefore postulated that the apparent protective effect of HER4 might be reflected by lower proliferative indices, while cases with a higher expression of HER1-3 would have higher proliferative indices.

HER1 and HER2 are both linked to poor prognostic factors in breast cancer [8,11-14]. Conflicting evidence is available on the prognostic significance of HER3: some studies show a relationship between HER3 and some markers of poor prognosis $[9,15,16]$, but others have shown that HER3 overexpression is consistent with a good prognostic outlook [17,18]. HER4 has more consistently been linked to good prognostic factors and a longer disease-free interval $[9,19,20]$. We have therefore studied HER1-4 expression in a cohort of patients in whom we have previously performed BrdU labelling to determine tumour proliferative indices and potential tumour doubling times [21] to investigate further the biological significance of HER1-4 overexpression with respect to cellular proliferation.

\section{Methods \\ Patients}

Eighty-nine patients who had a breast cancer more than $2 \mathrm{~cm}$ in diameter were recruited in the original study between 1989 and 1992. This size criterion was used to ensure that adequate tissue was available for analysis once diagnostic needs had been met. Only postmenopausal patients were entered, in view of the unknown embryotoxicity of bromodeoxyuridine (BrdU). The relevant ethics committees gave approval. Patients who had either breast conservation or mastectomy were included, as were those having adjuvant radiotherapy, chemotherapy or tamoxifen as part of protocols at that time. Follow-up status was obtained by review of patients' records, with further clarification from data held by the Scottish Cancer Intelligence Unit when there was any doubt over the cause of death. Calculation of bromodeoxyuridine labelling index (BLI) was possible in 84 patients. Four patients were lost to follow-up and two patients were excluded from survival analysis because they had metastasis at the time of diagnosis. Two patients had bilateral tumours; in these cases the tumour with the highest BLI value was included. Thus there were 78 cases in whom BLI and follow-up were available, with calculation of potential tumour doubling time $\left(T_{\text {pot }}\right)$ present for 55 of them. Material for evaluation of HER1-4 status was available for 55 of the labelled cases.

\section{Labelling with BrdU}

BrdU (200 mg) was administered as an intravenous bolus 4-10 hours before surgery. Tumour sample specimens were subjected to flow cytometric analysis; the subsequent calculation of $\mathrm{BLI}$ and $T_{\text {pot }}$ values has been described previously [21]. The BLI is presented as a percentage of tumour cells that became labelled with BrdU (that is, within the DNA-synthetic S phase of the cell cycle during exposure to $\mathrm{BrdU}$ ). The $T_{\text {pot }}$ is a measure of the minimum time to doubling of tumour size based on calculation of the length of the $S$ phase $\left(T_{s}\right)$ and is expressed in days.

\section{HER1-4 status}

HER1-4 status was determined in 55 patients by immunohistochemistry with specific antibodies, as described previously [9]. Scoring of membrane staining was performed with excellent agreement between observers (inter-class correlation coefficient 0.892).

\section{Statistics}

All statistical analysis was performed with the SPSS statistical package (version 9.0.0). Kaplan-Meier life-table analysis was undertaken with log-rank testing of differences in breast cancer-related survival (end-point breast cancer-specific death). BLI values in the 75th centile or higher were stratified as 'high' values, and $T_{\text {pot }}$ values in the 25th centile or lower were classified as 'low' values for the purpose of survival calculations. These cutoffs were used to identify the relevant 'high-risk' populations with regard to their proliferation indices. Multivariate analysis with Cox's multiple regression analysis was performed with the inclusion of known prognostic values such as grade, nodal status and tumour size. The Mann-Whitney test using mean ranks was used to evaluate any correlation between $\mathrm{BLI}$ values and HER1-4 status.

\section{Results \\ Patients}

The median age of patients $(n=78)$ included in the analysis was 64.6 years. Median follow-up available was 6.6 years (range $0.1-13$ years). There were 35 breast cancer-specific deaths and a further 15 deaths from unrelated causes (mainly cardiac/lung disease, with 4 deaths from other cancers). There were 69 ductal tumours, 4 lobular tumours and 5 other or non-specified types. There were 44 oestrogen receptor (ER)-positive and 30 ERnegative cases (4 unknown). The mean size of the tumours is $32.1 \pm 20.9 \mathrm{~mm}$ (mean $\pm \mathrm{SD}$ ), with a median of $27 \mathrm{~mm}$ (interquartile range $20-40 \mathrm{~mm}$ ). The nodal status was known on 74 patients; 40 had no nodal involvement, $23 \mathrm{had}$ one to three nodes involved and 11 had more than three nodes involved (Table 1). Forty-four patients received a mastectomy, and 34 patients had a wide local excision. For the patients with known adjuvant treatment details, 
Table 1

\begin{tabular}{|c|c|}
\hline Parameter & $n$ \\
\hline \multicolumn{2}{|l|}{ Tumour size } \\
\hline $\mathrm{T} 1$ & 31 \\
\hline T2 & 39 \\
\hline Т3 & 7 \\
\hline Unknown & 1 \\
\hline \multicolumn{2}{|l|}{ Grade } \\
\hline 1 & 14 \\
\hline 2 & 26 \\
\hline 3 & 36 \\
\hline Unknown & 2 \\
\hline \multicolumn{2}{|l|}{ Nodal status } \\
\hline Negative & 40 \\
\hline $1-3$ nodes & 23 \\
\hline $3+$ nodes & 11 \\
\hline Unknown & 4 \\
\hline \multicolumn{2}{|c|}{ Oestrogen receptor status } \\
\hline Positive & 44 \\
\hline Negative & 30 \\
\hline Unknown & 4 \\
\hline
\end{tabular}

93\% (69 of 74 ) received tamoxifen and only $4 \%$ (3 of 71 ) received chemotherapy.

\section{BLI and $\boldsymbol{T}_{\text {pot }}$}

The mean BLI was $4.0 \pm 3.1 \%$ (mean $\pm \mathrm{SD}$ ), with the median at 3.2\% (interquartile range 1.3-6.4\%). The mean $T_{\text {pot }}$ was $28.3 \pm 29.3$ days (mean \pm SD) with the median at 14.6 days (interquartile range 8.0-37.5 days). BLI and $T_{\text {pot }}$ are inversely related in a nonlinear fashion with a Spearman rank correlation coefficient of -0.938 (at a 0.01 significance level). For this reason and because of the smaller numbers in the $T_{\text {pot }}$ group, regression analysis and correlations with the HER group were performed with BLI only.

\section{HER1-4}

HER overexpression was defined as described by Witton and colleagues [9]; $13 \%$ (7 of 55) of patients were HER1 positive, 19\% (10 of 54) were HER2 positive, 20\% (10 of 51) were HER3 positive and 11\% (6 of 54) were HER4 positive (Table 2). Eighteen (48\%) patients were positive for at least one of HER1, HER2 or HER3 (HER1-3 positive).

HER1 positivity was significantly correlated with increased BLI values $(P=0.024)$; median BLI values for HER1-overexpressing tumours were 2.5-fold those for HER1-negative cases. BLI values for HER2 and HER3 positive tumours were respectively $42 \%$ and $69 \%$ higher than for tumours not expressing these proteins at high levels. Neither value reached significance levels $(P=0.216$ and $P=0.313)$.
Table 2

\begin{tabular}{|c|c|c|c|c|c|}
\hline HER & Status & $n$ & Median & Mean rank & $P$ \\
\hline \multirow[t]{2}{*}{ HER1 } & Positive & 7 & 6.3 & 40.71 & 0.024 \\
\hline & Negative & 48 & 2.5 & 26.15 & \\
\hline \multirow[t]{2}{*}{ HER2 } & Positive & 10 & 4.2 & 33.05 & 0.216 \\
\hline & Negative & 44 & 2.95 & 26.24 & \\
\hline \multirow[t]{2}{*}{ HER3 } & Positive & 10 & 5.25 & 30.25 & 0.313 \\
\hline & Negative & 41 & 3.1 & 24.96 & \\
\hline \multirow[t]{2}{*}{ HER4 } & Positive & 6 & 1.05 & 12.83 & 0.013 \\
\hline & Negative & 48 & 3.25 & 29.33 & \\
\hline \multirow[t]{2}{*}{ HER1-3 } & Positive & 18 & 4.4 & 34.33 & 0.041 \\
\hline & Negative & 37 & 2.5 & 24.92 & \\
\hline
\end{tabular}

$P$ values were obtained with the Mann-Whitney test.

Figure 1

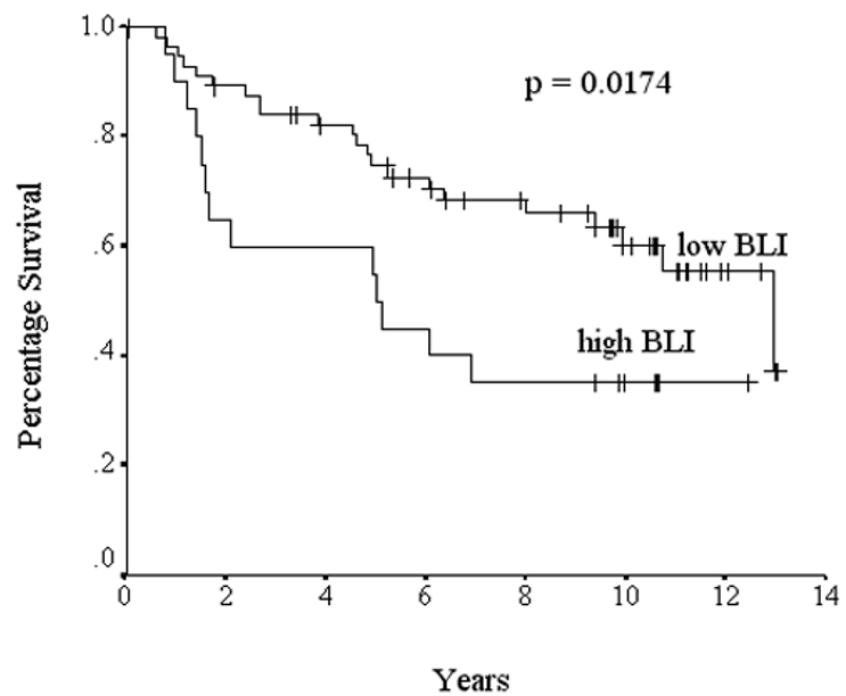

Survival curves (Kaplan-Meier) for bromodeoxyuridine labelling index (BLI). Cumulative survival differences between patients whose tumours had high BLI values (at least 75th centile; that is, 6.4\%) and low BLI values (below 75th centile). $P$ values represent log-rank differences in cumulative survival between the two groups.

HER2 and HER3 $(n=18)$ are considered, this group had significantly higher $\mathrm{BLI}$ values $(P=0.041)$ than patients with tumours that did not express these proteins.

Conversely, tumours with high HER4 expression showed $B L I$ values significantly lower than tumours not expressing HER4 $(P=0.013)$, with a median reduction in BLI of $65 \%$. 
Figure 2

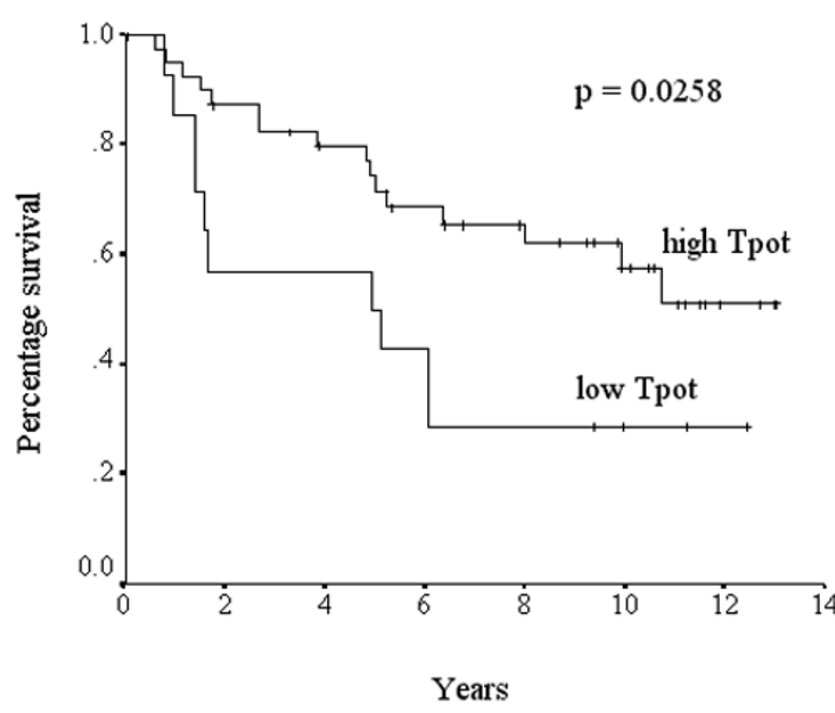

Survival curves (Kaplan-Meier) for potential tumour doubling time $\left(T_{\text {pot }}\right)$. Cumulative survival differences between patients whose tumours had low $T_{\text {pot }}$ values (25th centile or less; that is, 8.0 days) or high $T_{\text {pot }}$ values (more than 25th centile). $P$ values represent log-rank differences in cumulative survival between the two groups.

\section{Survival}

Patients with higher BLI values (75th centile or higher; $n=20$ ) had a significantly poorer prognosis in terms of survival (10-year survival 35\%) from breast cancer than patients with BLI values below the 75 th centile $(n=58$; 10-year survival 60\%; $p=0.0174$ [log-rank test]; Fig. 1).

Patients with low $T_{\text {pot }}$ times (25th centile or below; $n=14$ ) had significantly lower survival (10-year survival 29\%) than patients with $T_{\text {pot }}$ times above the 25th centile ( $n=41$; 10-year survival 58\%; $P=0.0258$ [log-rank test]; Fig. 2). Further stratification of $\mathrm{BLI}$ and $T_{\text {pot }}$ into other quartile groups did not show improved distinction in terms of survival (data not shown).

When BLI and HER status were included in Cox's multiple regression analysis along with known prognostic variables (Table 3), size and HER1-3 status were the only independent predictors of survival.

\section{Discussion}

Studies of tumour labelling index have shown significant correlations between high proliferation indices and poor outcome [22,23], although this is not always true in the context of a multivariate analysis [24,25]. More recently the proliferation marker Ki67, a nuclear antigen expressed in the G1, S, G2 and M cell phases but not in G0 [26], has been used as a proliferation marker. These methods provide 'static' information about the cell cycle at a single point in time but do not give any information about the rate
Table 3

\begin{tabular}{lc}
$\begin{array}{l}\text { Results of Cox's multivariate regression analysis for } \\
\text { bromodeoxyuridine labelling index (BLI), human epidermal } \\
\text { growth factor receptor (HER) status and known prognostic } \\
\text { variables }\end{array}$ & $P$ \\
\hline Variable $(n=48)$ & 0.155 \\
\hline Grade & 0.008 \\
Size & 0.283 \\
Nodal status & 0.197 \\
Oestrogen receptor status & 0.052 \\
BLI & 0.003 \\
HER1-3 status & 0.985 \\
HER4 status & \\
\hline
\end{tabular}

of progress of the cells through the cycle. Providing dynamic information about the rate of cell cycling might be a more accurate reflection of tumour growth because it permits the estimation of parameters such as the potential doubling time. With the use of flow cytometry and in vivo labelling with the thymidine analogue $\mathrm{BrdU}$ it is possible to obtain both BLI and $T_{\text {pot }}[27,28]$.

We have shown that tumours with either high BLI values or low $T_{\text {pot }}$ times have significantly poorer breast cancerspecific survival rates. However, together with other known prognostic factors, BLI was not shown to be an independent prognostic factor in multivariate analysis. This might reflect the small size of the present study rather than any failure of the method itself, because stage, grade and ER status were also not significant indices of survival in this study. Cutress and colleagues [29] followed up 75 patients with invasive breast cancer but did not show any significant correlation between proliferation data and outcome measures. A larger study of 129 patients showed a significant correlation between low proliferation indices and survival that persisted in multivariate analysis when known prognostic factors such as node status, age and size of the tumour were included [3].

Tumour growth, which we have sought to measure by calculating $T_{\text {pot }}$, is a balance between cell growth and cell loss and is therefore affected by factors such as oxygenation and apoptosis. BrdU labelling does not provide any information about cell loss, which is now recognised to be a significant factor in determining the actual growth of a tumour. Future measurements that include an estimate of both proliferation and cell loss might provide more accurate prognostic indices. The use of molecular profiling to identify tumours with differing proliferative and apoptotic signatures might provide valuable information in the future [30]. 
The use of proliferation indices has, however, provided us with a method of clarifying the varying effects of the HER4 family at a biological level. Our study shows a significant correlation between high BLI values and HER1 positivity. This is in keeping with previous published results [31]. It is also consistent with other studies with the proliferation marker Ki67 [32]. Interestingly, HER1 expression in bladder cancer is also associated with high BrdU indices [33]. We demonstrate a non-significant trend for HER2positive tumours to have a higher BLI. This is consistent with previously published results by ourselves and others $[21,34]$. However, there is evidence of a significant correlation between Ki67 and HER2 expression $[35,36]$.

There is no previous published evidence examining the relationship between HER3, HER4 and BLI. However, one study using Ki-67 showed a significant relationship between HER3 and HER4 positivity and decreasing Ki-67 levels [19], arguing that neither of these receptors is involved in directing proliferation. In terms of HER3 in this study we show a non-significant trend towards higher BLI values. In addition, when tumours positive for one or more of HER $1-3$ are taken as a group they show significantly higher proliferation rates. This is in contrast to the findings demonstrated with Ki67 [19] but is more in keeping with studies that have identified a poor prognostic role for HER3 $[9,16]$.

We demonstrate a significant inverse correlation between HER4 positivity and BLI values. This suggests that HER4 expression in breast cancer might be involved in an antiproliferative role. Although a proliferative role for HER4 (in keeping with the other HER family members) has been suggested [37,38], there is other evidence to the contrary. Our previous results suggest that HER4 is very rarely coexpressed with other HER receptors [9]. Data from cell lines have shown that activation of HER4 receptor homodimers results in a weak biological response in comparison with other receptor combinations [10]. Other cell line work has shown that HER4 is necessary for mediating the anti-proliferative and differentiation responses elicited by neuregulin [39]. Indeed, in normal breast tissue HER4 seems to have a critical role in the late differentiation of mammary gland function [40]. Thus, this evidence seems to support the association that HER4 has with improved breast cancer survival times [9]. Some of the conflicting evidence might be explained by the various isoforms of HER4 [41] or by the inherent difficulty of separating HER4 responses from those of the other family members.

\section{Conclusions}

We have provided a biological correlate to substantiate the deleterious effect of HER1-3 and the protective role for HER4. This possibility of differing roles within the the choice of future anti-HER treatment options. Currently the HER2 monoclonal antibody Herceptin (trastzumab) is being used successfully to treat patients with strongly HER2-positive metastatic breast cancer [42]. Our results suggest that the use of pan-HER inhibitors might not be advised in tumours that are positive for HER4, and that more individually directed therapies are needed.

\section{Competing interests}

None declared.

\section{References}

1. Amadori D, Silvestrini R: Prognostic and predictive value of thymidine labelling index in breast cancer. Breast Cancer Res Treat 1998, 51:267-281.

2. Rew DA, Wilson GD: Cell production rates in human tissues and tumours and their significance. Part 1: an introduction to the techniques of measurement and their limitations. Eur $J$ Surg Oncol 2000, 26:227-238.

3. Goodson WH III, Moore DH, Ljung BM, Chew K, Mayall B, Smith HS, Waldman FM: The prognostic value of proliferation indices: a study with in vivo bromodeoxyuridine and Ki-67. Breast Cancer Res Treat 2000, 59:113-123.

4. Yarden $\mathrm{Y}$, Sliwkowski $\mathrm{MX}$ : Untangling the ErbB signalling network. Nat Rev Mol Cell Biol 2001, 2:127-137.

5. Lemoine NR, Barnes DM, Hollywood DP, Hughes CM, Smith P, Dublin E, Prigent SA, Gullick WJ, Hurst HC: Expression of the ERBB3 gene product in breast cancer. $\mathrm{Br} J$ Cancer 1992, 66: 1116-1121.

6. Sainsbury JR, Farndon JR, Sherbet GV, Harris AL: Epidermalgrowth-factor receptors and oestrogen receptors in human breast cancer. Lancet 1985, i:364-366.

7. Suo Z, Risberg B, Kalsson MG, Willman K, Tierens A, Skovlund E, Nesland JM: EGFR family expression in breast carcinomas. cerbB-2 and c-erbB-4 receptors have different effects on survival. J Pathol 2002, 196:17-25.

8. Slamon DJ, Clark GM, Wong SG, Levin WJ, Ullrich A, McGuire WL: Human breast cancer: correlation of relapse and survival with amplification of the HER-2/neu oncogene. Science 1987, 235:177-182.

9. Witton CJ, Reeves JR, Going JJ, Cooke TG, Bartlett JM: Expression of the HER1-4 family of receptor tyrosine kinases in breast cancer. J Pathol 2003, 200:290-297.

10. Alroy I, Yarden Y: The ErbB signaling network in embryogenesis and oncogenesis: signal diversification through combinatorial ligand-receptor interactions. FEBS Lett 1997, 410:83-86.

11. Klijn JG, Berns PM, Schmitz PI, Foekens JA: The clinical significance of epidermal growth factor receptor (EGF-R) in human breast cancer: a review on $\mathbf{5 2 3 2}$ patients. Endocr Rev 1992, 13:3-17.

12. Ross JS, Fletcher JA: The HER-2/neu oncogene in breast cancer: prognostic factor, predictive factor, and target for therapy. Stem Cells 1998, 16:413-428.

13. Cooke T, Reeves J, Lannigan A, Stanton P: The value of the human epidermal growth factor receptor-2 (HER2) as a prognostic marker. Eur J Cancer 2001, 37 Suppl 1:3-10.

14. Sainsbury JR, Farndon JR, Needham GK, Malcolm AJ, Harris AL: Epidermal-growth-factor receptor status as predictor of early recurrence of and death from breast cancer. Lancet 1987, 1: 1398-1402.

15. Naidu R, Yadav M, Nair S, Kutty MK: Expression of c-erbB3 protein in primary breast carcinomas. $\mathrm{Br} J$ Cancer 1998, 78: 1385-1390.

16. Travis A, Pinder SE, Robertson JF, Bell JA, Wencyk P, Gullick WJ, Nicholson RI, Poller DN, Blamey RW, Elston CW, Ellis IO: CerbB-3 in human breast carcinoma: expression and relation to prognosis and established prognostic indicators. $\mathrm{Br} J$ Cancer 1996, 74:229-233.

17. Pawlowski V, Revillion F, Hebbar M, Hornez L, Peyrat JP: Prognostic value of the type I growth factor receptors in a large series of human primary breast cancers quantified with a real-time reverse transcription-polymerase chain reaction assay. Clin Cancer Res 2000, 6:4217-4225. 
18. Quinn CM, Ostrowski JL, Lane SA, Loney DP, Teasdale J, Benson FA: c-erbB-3 protein expression in human breast cancer: comparison with other tumour variables and survival. Histopathology 1994, 25:247-252.

19. Knowlden JM, Gee JM, Seery LT, Farrow L, Gullick WJ, Ellis IO, Blamey RW, Robertson JF, Nicholson RI: c-erbB3 and c-erbB4 expression is a feature of the endocrine responsive phenotype in clinical breast cancer. Oncogene 1998, 17:1949-1957.

20. Suo Z, Risberg B, Kalsson MG, Willman K, Tierens A, Skovlund E, Nesland JM: EGFR family expression in breast carcinomas. cerbB-2 and c-erbB-4 receptors have different effects on survival. J Patho/ 2002, 196:17-25.

21. Stanton PD, Cooke TG, Forster G, Smith D, Going JJ: Cell kinetics in vivo of human breast cancer. Br J Surg 1996, 83:98-102.

22. Frierson HF Jr: Ploidy analysis and S-phase fraction determination by flow cytometry of invasive adenocarcinomas of the breast. Am J Surg Pathol 1991, 15:358-367.

23. Tubiana M, Pejovic MH, Chavaudra N, Contesso G, Malaise EP: The long-term prognostic significance of the thymidine labelling index in breast cancer. Int J Cancer 1984, 33:441-445.

24. Cooke TG, Stanton PD, Winstanley J, Murray GD, Croton R, Holt $\mathrm{S}$, George WD: Long-term prognostic significance of thymidine labelling index in primary breast cancer. Eur $J$ Cancer 1992, 28:424-426.

25. Stanton PD, Cooke TG, Oakes SJ, Winstanley J, Holt S, George WD, Murray GD: Lack of prognostic significance of DNA ploidy and $S$ phase fraction in breast cancer. $B r J$ Cancer 1992, 66: 925-929.

26. Gerdes J, Lemke H, Baisch H, Wacker HH, Schwab U, Stein H: Cell cycle analysis of a cell proliferation-associated human nuclear antigen defined by the monoclonal antibody Ki-67. J Immunol 1984, 133:1710-1715.

27. Begg AC, McNally NJ, Shrieve DC, Karcher H: A method to measure the duration of DNA synthesis and the potential doubling time from a single sample. Cytometry 1985, 6:620626.

28. White RA, Terry NH, Meistrich ML, Calkins DP: Improved method for computing potential doubling time from flow cytometric data. Cytometry 1990, 11:314-317.

29. Cutress RI, Mullee MA, Royle GT, Rew DA: Clinical outcome and bromodeoxyuridine-derived proliferation indices in 75 invasive breast carcinomas. Eur J Surg Oncol 2000, 26:747750.

30. van de Vijver MJ, He YD, van't Veer LJ, Dai H, Hart AA, Voskuil DW, Schreiber GJ, Peterse JL, Roberts C, Marton MJ, Parrish M, Atsma D, Witteveen A, Glas A, Delahaye L, van der Velde T, Bartelink H, Rodenhuis S, Rutgers ET, Friend SH, Bernards R: A gene-expression signature as a predictor of survival in breast cancer. N Engl J Med 2002, 347:1999-2009.

31. Robertson KW, Reeves JR, Smith G, Keith WN, Ozanne BW, Cooke TG, Stanton PD: Quantitative estimation of epidermal growth factor receptor and c-erbB-2 in human breast cancer. Cancer Res 1996, 56:3823-3830.

32. Nicholson RI, McClelland RA, Finlay P, Eaton CL, Gullick WJ, Dixon AR, Robertson JF, Ellis IO, Blamey RW: Relationship between EGF-R, c-erbB-2 protein expression and Ki67 immunostaining in breast cancer and hormone sensitivity. Eur J Cancer 1993, 29A:1018-1023.

33. Sauter G, Haley J, Chew K, Kerschmann R, Moore D, Carroll P, Moch H, Gudat F, Mihatsch MJ, Waldman F: Epidermal-growthfactor-receptor expression is associated with rapid tumor proliferation in bladder cancer. Int J Cancer 1994, 57:508-514.

34. Moriki T, Takahashi T, Kataoka H, Hiroi M, Yamane T, Hara H: Proliferation marker MIB-1 correlates well with proliferative activity evaluated by BrdU in breast cancer: an immunohistochemical study including correlation with PCNA, p53, c-erbB-2 and estrogen receptor status. Pathol Int 1996, 46: 953-961.

35. loachim E, Kamina S, Athanassiadou S, Agnantis NJ: The prognostic significance of epidermal growth factor receptor (EGFR), C-erbB-2, Ki-67 and PCNA expression in breast cancer. Anticancer Res 1996, 16:3141-3147.

36. Dowsett M, Harper-Wynne C, Boeddinghaus I, Salter J, Hills M, Dixon M, Ebbs S, Gui G, Sacks N, Smith I: HER-2 amplification impedes the antiproliferative effects of hormone therapy in estrogen receptor-positive primary breast cancer. Cancer Res 2001, 61:8452-8458.
37. Tang CK, Concepcion XZ, Milan M, Gong X, Montgomery E, Lippman ME: Ribozyme-mediated down-regulation of ErbB-4 in estrogen receptor-positive breast cancer cells inhibits proliferation both in vitro and in vivo. Cancer Res 1999, 59:53155322.

38. Wang LM, Kuo A, Alimandi M, Veri MC, Lee CC, Kapoor V, Ellmore $\mathrm{N}$, Chen $\mathrm{XH}$, Pierce JH: ErbB2 expression increases the spectrum and potency of ligand-mediated signal transduction through ErbB4. Proc Natl Acad Sci U S A 1998, 95: 6809-6814.

39. Sartor Cl, Zhou H, Kozlowska E, Guttridge K, Kawata E, Caskey L, Harrelson J, Hynes N, Ethier S, Calvo B, Earp HS, III: Her4 mediates ligand-dependent antiproliferative and differentiation responses in human breast cancer cells. Mol Cell Biol 2001 21:4265-4275.

40. Jones FE, Welte $T, F u X Y$, Stern DF: ErbB4 signaling in the mammary gland is required for lobuloalveolar development and Stat5 activation during lactation. J Cell Biol 1999, 147:7788.

41. Gullick WJ: c-erbB-4/HER4: friend or foe? J Patho/ 2003, 200: 279-281.

42. Baselga J: Herceptin alone or in combination with chemotherapy in the treatment of HER2-positive metastatic breast cancer: pivotal trials. Oncology 2001, 61 Suppl 2:14-21.

\section{Correspondence}

John MS Bartlett, Endocrine Cancer Group, University Department of Surgery, Level II, Queen Elizabeth Building, Glasgow Royal Infirmary, Glasgow G31 2ER, UK. Tel: +44 141211 5436; fax: +44 141552 3229; e-mail: j.m.bartlett@clinmed.gla.ac.uk 